\title{
Corrosion Resistance of Epoxy Coatings Modified by Bis-Silane Prepolymer on Aluminum Alloy
}

\author{
Diping Zeng ${ }^{1,2,3, *}$, Zhiyi Liu ${ }^{2}$, Lihua Zou ${ }^{1,3}$ and Haijiang Wu ${ }^{1,3}$ \\ 1 Department of Mechanical and Energy Engineering, Shaoyang University, Shaoyang 422000, China; \\ zoulihua-mail@163.com (L.Z.); hjwu@hnsyu.edu.cn (H.W.) \\ 2 School of Materials Science and Engineering, Central South University, Changsha 410083, China; \\ liuzhiyi@csu.edu.cn \\ 3 Key Laboratory of Hunan Province for Efficient Power System and Intelligent Manufacturing, \\ Shaoyang University, Shaoyang 422000 , China \\ * Correspondence: zengdiping@csu.edu.cn
}

check for updates

Citation: Zeng, D.; Liu, Z.; Zou, L.; $\mathrm{Wu}, \mathrm{H}$. Corrosion Resistance of Epoxy Coatings Modified by Bis-Silane Prepolymer on Aluminum Alloy. Coatings 2021, 11, 842. https:// doi.org/10.3390/coatings11070842

Academic Editor: Ludmila

B. Boinovich

Received: 22 June 2021

Accepted: 11 July 2021

Published: 13 July 2021

Publisher's Note: MDPI stays neutral with regard to jurisdictional claims in published maps and institutional affiliations.

Copyright: (c) 2021 by the authors. Licensee MDPI, Basel, Switzerland. This article is an open access article distributed under the terms and conditions of the Creative Commons Attribution (CC BY) license (https:// creativecommons.org/licenses/by/ $4.0 /)$.

\begin{abstract}
In this communication, a bis-silane prepolymer was used to modify epoxy resin, aiming to enhance the corrosion resistance of epoxy coatings on aluminum alloy substrates. The bis-silane prepolymer was prepared by tetraethoxysilane (TEOS) and $\gamma$-glycidoxypropyl trimethoxysilane (GPTMS). The corrosion behavior of silane-epoxy coatings was studied. Compared with silane monomer-modified epoxy coatings, bis-silane-modified epoxy coatings have lower coating capacitance $\left(C_{c}\right)$, higher charge transfer resistances $\left(R_{d l}\right)$, and lower double layer capacitance $\left(C_{d l}\right)$ during long-time immersion. It indicates that bis-silane-modified epoxy coating has stronger waterproof permeability and substrate corrosion protection ability. In addition, due to the leaching of the silane component and cross-linking reaction between different silanes during the immersion process, the bis-silane-modified epoxy coatings exhibit much stronger "self-healing" ability.
\end{abstract}

Keywords: bis-silane prepolymer; silane-epoxy coatings; aluminum alloy; EIS

\section{Introduction}

Corrosion is the most common failure mode of exposed metal and its alloy structures. In order to protect or slow down the corrosion process, protective coatings are typically applied to metal surfaces [1-4]. Coated epoxy organic coatings on metal surfaces are considered to be one of the most promising ways to protect metals from corrosion [5-9]. However, after long immersion in the corrosion solution, water can easily penetrate through the hydroxyl groups or pores in the epoxy coating, damaging the epoxy coating's structure and its corrosion protection performance [10-12]. To solve this problem, the epoxy coating was modified by silane monomers (such as tetraethoxy silane, $\gamma$-aminopropyltrimethoxy silane, $\gamma$-glycidyl oxypropyl trimethoxysilane, and 3-Glycidoxy propyltrimethoxy silane, et al.) [11-15]. These silane components in the coating can improve the adhesion performance, reduce the coating's water absorption, and finally enhance the corrosion resistance of the coating system.

But, when the silane monomer directly modified the epoxy resin, the hydrolytic activity of the silane monomer was too large, which reduces the long-term protective effect of the coatings [16]. Generally, the silane monomer was pre-hydrolyzed and condensed to form Si-O-Si network before being mixed into the polymer resin $[17,18]$. Ji et al. [14] modified the epoxy polyamide with GPTMS prepolymer. Studies have shown that the silane-modified epoxy coating system has better corrosion resistance, and the corrosion resistance of the coating increases with the increase of the amount of silane monomer. Bakhshandeh et al. [18] used TEOS prepolymer to modify the epoxy resin functionalized with 3-aminopropyltriethoxysilane (APTES), and the experiment showed that the epoxy coating through the modified treatment effectively prevents the penetration of the electrolyte and reduces the corrosion rate. After pre-hydrolysis treatment, the silane monomer 
will not completely polymerize through the hydrolysis polycondensation reaction, and there are some alkoxy groups that are not completely hydrolyzed. These incompletely hydrolyzed alkoxy groups will undergo a hydrolysis-polycondensation reaction during the subsequent immersion process, forming new Si-O-Si and Si-O-C structures, increasing the density of the coating $[19,20]$. Different silanes have different hydrolysis activities under the same hydrolysis conditions. Then, in the mixed silane prepolymer formed by mixing different silanes, it is easy to synthesize a silane prepolymer that is partially hydrolyzed and polycondensed but still contains hydrolytically active alkoxy groups. In this work, a bis-silane prepolymer, formed by tetraethoxy silane (TEOS) and $\gamma$-glycidoxypropyl trimethoxy silane (GPTMS), was used to modify the epoxy resin, and a silane-epoxy coating was prepared on $\mathrm{Al}-\mathrm{Zn}-\mathrm{Mg}-\mathrm{Cu}$ alloy. The corrosion resistance of coatings in a $3.5 \mathrm{wt} \%$ $\mathrm{NaCl}$ solution was investigated using electrochemical impedance spectroscopy (EIS).

\section{Experimental Details}

\subsection{Sample Preparation}

The tests were carried out on an $\mathrm{Al}-\mathrm{Zn}-\mathrm{Mg}-\mathrm{Cu}$ alloy samples. The composition of this alloy is listed in Table 1. The surface of the samples (50 $\mathrm{mm} \times 50 \mathrm{~mm} \times 2 \mathrm{~mm}$ ) was ground with up to 1200 grit $\mathrm{SiC}$ abrasive papers, then degreased in pure acetone (Aladdin Industrial Corporation, Shanghai, China, analytically pure) before deposition and washed with deionized water prior to the coating.

Table 1. Chemical composition of investigated alloys (mass fraction, $\%$ ).

\begin{tabular}{ccccccc}
\hline $\mathbf{Z n}$ & $\mathbf{M g}$ & $\mathbf{C u}$ & $\mathbf{C r}$ & $\mathbf{F e}$ & $\mathrm{Si}$ & Al \\
\hline 6.28 & 2.19 & 1.6 & 0.15 & $0.4-0.6$ & $0.4-0.6$ & Bal. \\
\hline
\end{tabular}

\subsection{Formation of Silane-Epoxy Hybrid Coating}

\subsubsection{Preparation of Bis-Silane Prepolymer}

The preparation of pre-hydrolyzed bis-silane prepolymer solution was carried out as mentioned in our previous work: first, $40 \mathrm{~mL}$ of tetraethoxysilane (TEOS, Sigma Adrich, St. Louis, MO, USA, >95\%) in $20 \mathrm{~mL}$ of ethanol was stirred at $25^{\circ} \mathrm{C}$ for $10 \mathrm{~min}$. Second, $12 \mathrm{~mL}$ of GPTMS (Sigma Adrich, $>95 \%$ ) was added, and nitric acid was added drop by drop (the mass fraction is about $68 \%$, analytically pure) to obtain the desirable $\mathrm{pH}$ value (pH 3.5) [21]. The solution was stirred at $25^{\circ} \mathrm{C}$ for $45 \mathrm{~min}$. Finally, $10 \mathrm{~mL}$ distilled water was added, and stirred at $25^{\circ} \mathrm{C}$ for $24 \mathrm{~h}$ and aged above $72 \mathrm{~h}$ before use. The TEOS prepolymer solution and GPTMS prepolymer solution were prepared with the same method, in which, ethanol, TEOS (or GPTMS), and deionized water were mixed in a volume ratio of 4:2:1. All the solutions were stirred on a magnetic stirrer at a medium stirring speed.

\subsubsection{Preparation of Silane-Epoxy Coatings}

All of the silane-modified coatings were prepared using the following process. First, bisphenol A diglycidylether (epoxy resin E44, Aladdin Industrial Corporation, $>95 \%$ ) and polyamide 560 (Aladdin Industrial Corporation, $>95 \%$ ) were dissolved in a solvent at a mass ratio of 2:1 to form an epoxy/polyamide solution. The solvent used was xylene (Aladdin Industrial Corporation, analytically pure) and n-propanol (Aladdin Industrial Corporation, analytically pure) mixed in a volume ratio of 2:1; the mass ratio of the solvent to bisphenol A diglycidylether was 1:1. Second, pre-hydrolyzed silane solution was added into the epoxy/polyamide solution; the mass ratio of the silane solution to the epoxy resin was 1:1. Stirring was continued at $45^{\circ} \mathrm{C}$ for $1 \mathrm{~h}$ to form a silane-modified epoxy resin organic polymer solutions. Third, the $\mathrm{Al}-\mathrm{Zn}-\mathrm{Mg}$-Cu alloy was dip-coated in the modified solution for $10 \mathrm{~s}$, and quickly taken out and dried at room temperature environment for $12 \mathrm{~h}$ and cured in an oven at $100{ }^{\circ} \mathrm{C}$ for 90 min to obtain epoxy coating. In this paper, TEOS modified the epoxy coating named TEOS-PE, GPTMS modified the epoxy coating named GPTMS-PE, and bis-silane prepolymer modified the epoxy coating named BISE-PE. 
The thickness of the coatings evaluated by thickness gauge TT260 (Beijing Times Sihe Technology Co., Ltd., Beijing, China) is about $35 \pm 5 \mu \mathrm{m}$.

\subsection{Electrochemical Measurements}

The electrochemical experiments were carried out in a $3.5 \mathrm{wt} . \% \mathrm{NaCl}$ solution (pH 7) at room temperature. The electrochemical impedance spectroscopy measurements were collected using MULTI AUTOLAB M204 electrochemical workstation (Metrohm, Herisau, Switzerland). A saturated calomel electrode (SCE) was used as the reference electrode, and platinum plate as the counter electrode. The sample is used as the working electrode, and the geometric area is $1 \mathrm{~cm}^{2}$. The electrochemical impedance spectroscopy measurements were carried out at the value of OCP, and the applied sinusoidal signal RMS amplitude was $10 \mathrm{mV}$ over the frequency range from $10^{5}$ to $10^{-2} \mathrm{~Hz}$. After immersing in the electrolyte for about $10 \mathrm{~min}$ to reach a stable open circuit potential (OCP), potentiodynamic polarization measurement was performed. The scan rate of potentiodynamic polarization measurements was $0.2 \mathrm{mV} / \mathrm{s}$. Three similar samples were measured for each type of coating to check the reproducibility of the results.

\section{Results and Discussion}

\subsection{Potentiodynamic Polarization}

Figure 1 shows the potentiodynamic polarization curves of the coatings in a $3.5 \mathrm{wt} . \%$ $\mathrm{NaCl}$ solution. Using the Metrohm Autolab Nova 2.1 analysis software of MULTI AUTO M204 electrochemical work station, the corrosion dynamics parameters were derived from the approximate cathode Tafel region (ranging from -120 to $-60 \mathrm{mV}$ versus the corrosion potential [6]) and extrapolated back to the corrosion potential (as shown in Figure 2). The results are listed in Table 2 . The corrosion current density $\left(\mathrm{i}_{\text {corr }}\right.$ ) related to the corrosion rate, and a lower $\mathrm{i}_{\text {corr }}$ indicated better corrosion resistance. $R_{\mathrm{p}}$ reflected the coating's ability to block electrolyte penetration; the larger the $R_{p}$, the stronger the coating system's blocking effect on corrosion ions. It shows that $\mathrm{PE}$ (pure epoxy coating) coating has the largest $\mathrm{i}_{\text {corr }}$ and smallest $\mathrm{R}_{\mathrm{p}}$. Compared with PE coating, $\mathrm{i}_{\text {corr }}$ of TEOS-PE coating and GPTMS-PE coating decreased from $\sim 10^{-9}$ to $\sim 10^{-10} \mathrm{~A} / \mathrm{cm}^{2}, \mathrm{R}_{\mathrm{p}}$ increased from $\sim 10^{6}$ to $\sim 10^{7} \Omega$; $\mathrm{i}_{\text {corr }}$ of BISE-PE coating decreased from $\sim 10^{-9}$ to $\sim 10^{-11} \mathrm{~A} / \mathrm{cm}^{2}$, and $\mathrm{R}_{\mathrm{p}}$ increased from $\sim 10^{6}$ to $\sim 10^{8} \Omega$, indicating that bis-silane prepolymer-modified epoxy/polyamide system coating has the best corrosion resistance.

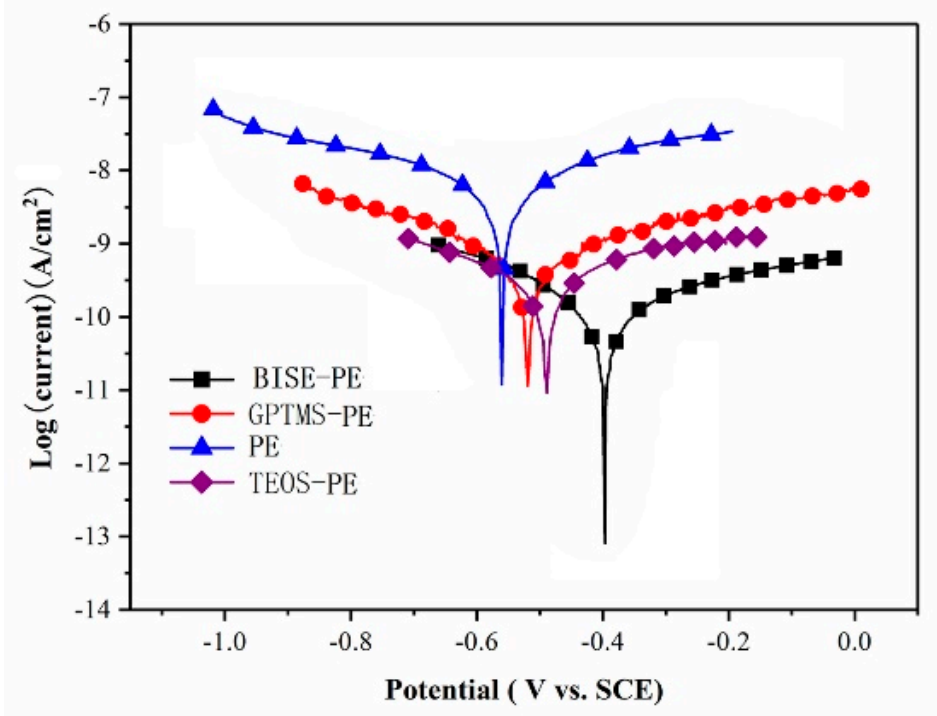

Figure 1. Polarization curves of an $\mathrm{Al}-$ alloy coated with different PE-coatings. 


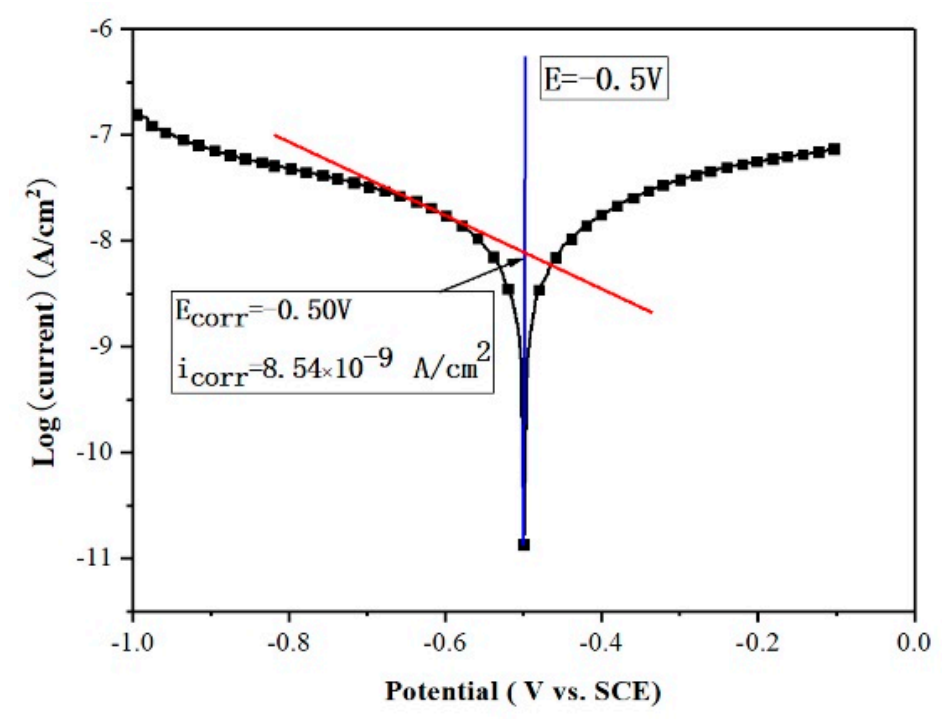

Figure 2. The extrapolation of linear Tafel segments of the cathodic curve.

Table 2. Corrosion dynamics parameters of samples.

\begin{tabular}{cccc}
\hline Sample & $\mathbf{E}_{\text {corr }}(\mathbf{V v s} \mathbf{S C E})$ & $\left.\mathbf{i}_{\text {corr }} \mathbf{( A / \mathbf { c m } ^ { 2 }}\right)$ & $\mathbf{R}_{\mathbf{p}}(\boldsymbol{\Omega})$ \\
\hline PE & -0.50 & $8.54 \times 10^{-9}$ & $7.65 \times 10^{6}$ \\
TEOS-PE & -0.66 & $3.48 \times 10^{-10}$ & $9.71 \times 10^{7}$ \\
GPTMS-PE & -0.68 & $5.88 \times 10^{-10}$ & $7.09 \times 10^{7}$ \\
BISE-PE & -0.42 & $8.73 \times 10^{-11}$ & $4.37 \times 10^{8}$ \\
\hline
\end{tabular}

\subsection{EIS}

Using electrochemical impedance spectroscopy (EIS) to detect coating failures, one can clearly understand the failure process of coatings and the water transport behavior in coatings [4,22-24]. Figure 3 shows the Bode plots of pure and silane-modified epoxy coatings at different immersion times. Within $30 \mathrm{~min}$ of immersion, in the medium and high frequency range, the slope of the impedance modulus of the four coatings in the Bode diagram basically remains at -1 , the phase angle of the coating is about $90^{\circ}$, and the coating exhibits typical capacitive behavior. In the low-frequency region, the phase angle drops and resistance behavior appears. At this time, the coating is equivalent to a barrier layer with a higher coating resistance and a lower coating capacitance. There is no reaction process on the surface of the substrate (such as charge transfer, electric double layer and ion diffusion, etc.)

With the immersion time prolonged for PE coating, the low-frequency impedance value dropped sharply from $\sim 10^{10}$ to $\sim 10^{7} \Omega \cdot \mathrm{cm}^{2}$ after only one day of immersion, and then continued to decrease for a longer immersion time (Figure 3a). The phase angle also decreased during the immersion. Meanwhile, second time constant appeared in low-frequencies region after one day of immersion, indicating that corrosive ions had passed through the organic coating to reach the substrate, and a corrosion reaction has occurred at the coating/metal interface. After 7 days of immersion, an extra time constant appears at low frequencies, which is caused by the mass transfer limitation of corrosion products through the epoxy resin coating. Meanwhile, the low-frequency impedance value, which characterizes the barrier performance of the coating to water, also dropped sharply (Figure 3a), indicating that the corrosion protection performance of the coating was rapidly weakened. 

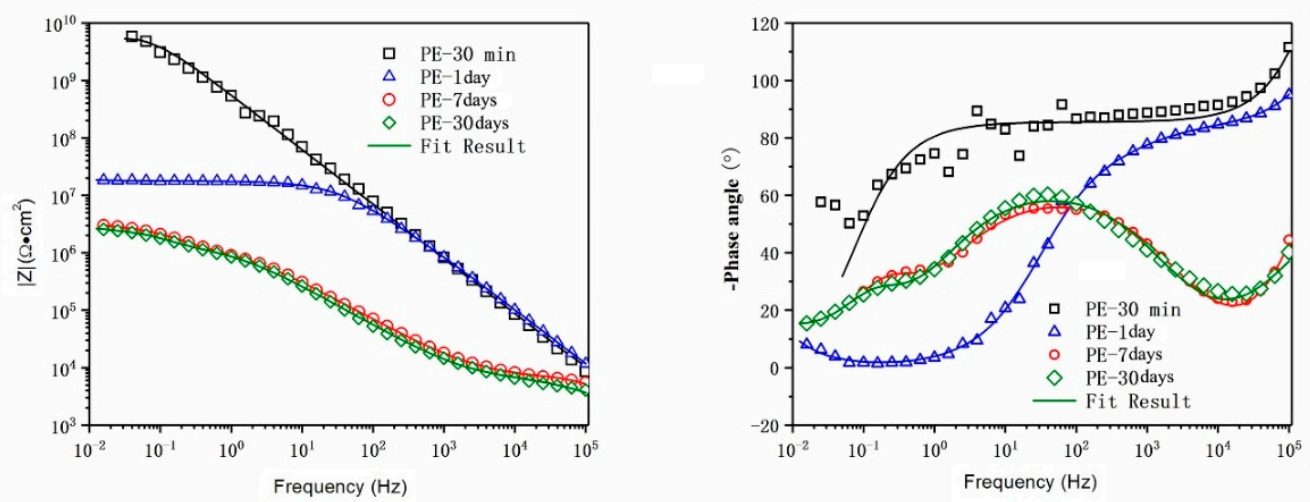

(a)
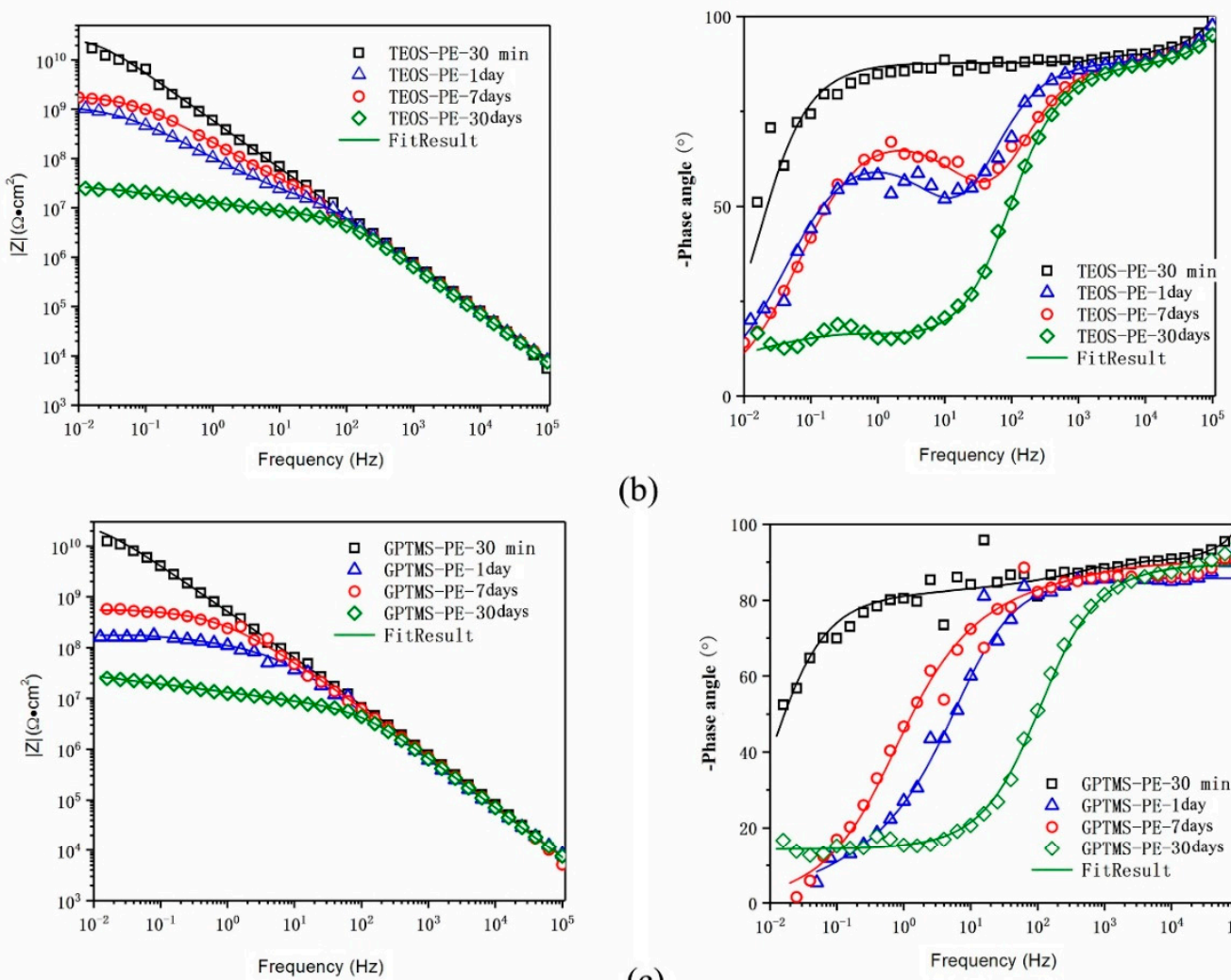

(b)
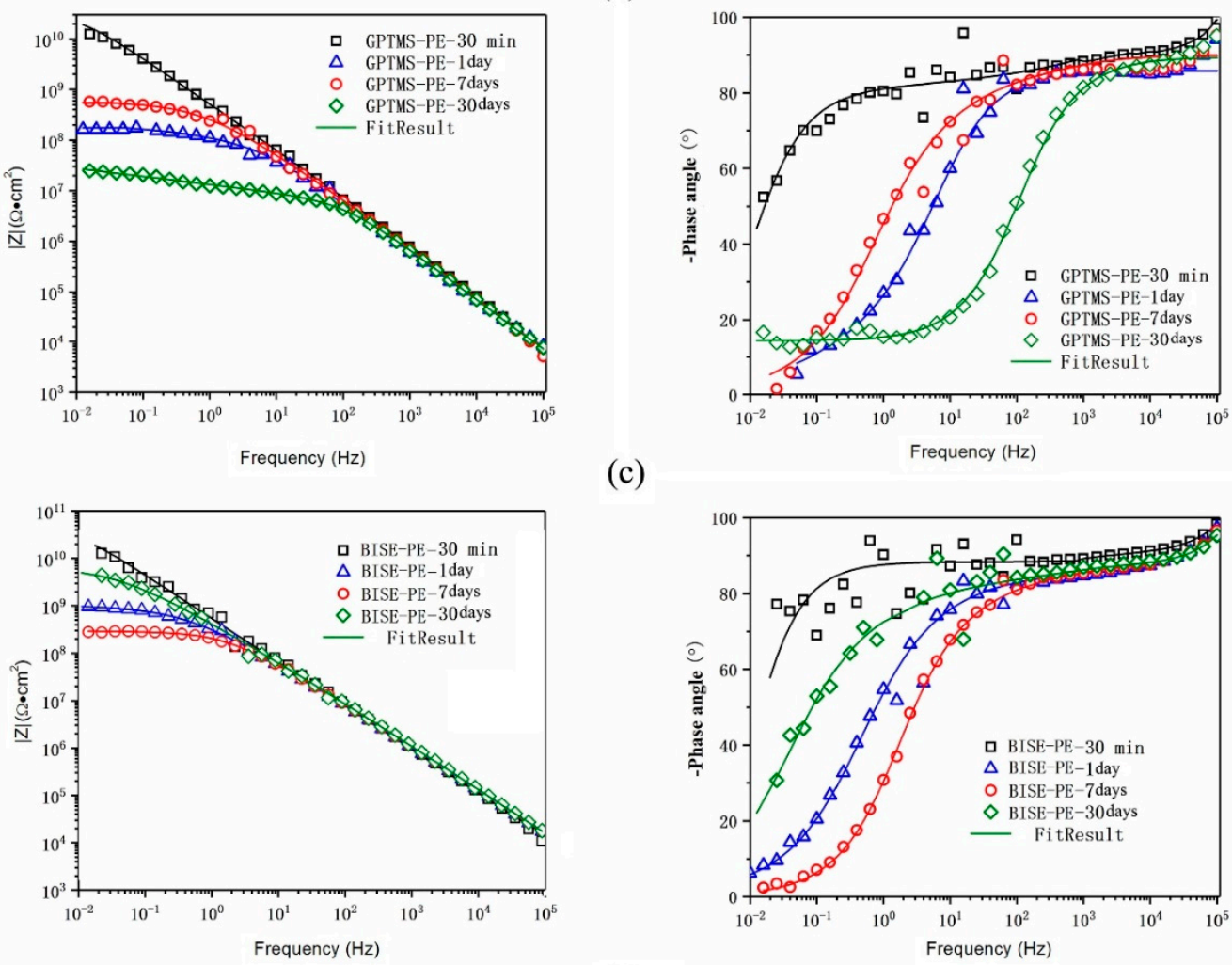

(d)

Figure 3. Typical Bode plots of pure (a), TEOS-modified (b), GMTPS-modified (c), and bis-silane (d) modified epoxy coatings on $\mathrm{Al}$-alloy during immersion in a $3.5 \mathrm{wt} . \% \mathrm{NaCl}$ solution. 
The low-frequency impedance value of silane-modified epoxy coating systems also decreased after immersion for 1 day. Owing to the enhanced barrier effect on water diffusion, the rate of decrease was much slower than that of the PE coating. After 7 days of continuous immersion, the impedance value rebounded (see Figure $3 b-d$ ). After immersing for 30 days, the final impedance value of TEOS-PE and GPTMS-PE coatings is about 2 orders of magnitude higher than that of PE-coating system (Figure $3 b, c)$, and the BISE-PE coating's final impedance value is about 3 orders of magnitude higher than that of PEcoating system (Figure 3d). The low-frequency impedance represents the total resistance of the electrolyte in the micropores or capillary channels of the coating, which will decrease due to the penetration of electrolyte. Impedance reduction means the failure of the coating, and rebound means self-healing of the coating system $[25,26]$. A large number of studies have shown that the self-healing performance of the coating is related to the re-hydrolysis and polycondensation reaction of the incompletely hydrolyzed siloxane in the coating. During the continuous immersion process, the incompletely hydrolyzed siloxane forms a new Si-O-Si cross-linked network $[7,12,27,28]$ in the coating through the hydrolysiscondensation reaction, and thus the coating structure is strengthened, increasing the barrier effect to water, oxygen, and corrosive ions.

As shown in Figure 3, the low-frequency impedance value of silane monomer-modified epoxy coating decreased to $\sim 10^{7} \Omega \cdot \mathrm{cm}^{2}$ after the self-healing period (see Figure $3 \mathrm{~b}, \mathrm{c}$, after 30 days), while the bis-silane-modified epoxy coatings gradually increased to $\sim 10^{10} \Omega \cdot \mathrm{cm}^{2}$ (Figure 3d). It showed that, for silane monomer-modified coatings, the hydrolysable alkoxy groups were depleted after a long period of immersion and the coating degraded and lost its corrosion resistance as the immersion time increased. However, for BISE-PE coating, because of the hydrolysis polycondensation reaction between silanes, there may be three types of prepolymers, i.e., the long-chain molecules of prepolymer formed by TEOS and GPTMS, the short-chain molecules of incomplete hydrolysis TEOS or GPTMS. With the prolongation of immersion time, the cross-linking reaction between silanes causes phase recombination [28]. The hydrolyzable alkoxy group in the bis-silane-modified epoxy coatings undergoes hydrolysis condensation reaction again to form a denser Si-O-Si cross-linking network, showing obvious "self-healing" characteristics, which makes the coating have a stronger structure and higher water resistance.

To further analyze the impedance data, EIS data analysis was conducted by Zview 3.1. Three typical equivalent circuits (EECs) (as shown in Figure 4) were proposed based on the goodness of fit at different immersion stages (the relative standard error within $10 \%$, or the sum of the squares of the residuals is in the order of $10^{-3}$ ). In order to obtain more accurate fitting results, constant phase elements (CPEs) were used to replace the capacitances in the EECs. The impedance of CPE was defined by the following equation [12,24,27]:

$$
\mathrm{Z}_{\mathrm{CPE}}=\frac{1}{\mathrm{Y}_{0}(\mathrm{j} \omega)^{\mathrm{n}}}
$$

where " $\mathrm{Y}_{0}$ " is the CPE constant, " $\omega$ "is the angular frequency, " $\mathrm{j}$ " is the imaginary number, and " $n$ " is the CPE power. The value of capacitances, $C_{c}$ and $C_{d l}$ were calculated from the following equation [27]:

$$
\begin{aligned}
C_{c} & =\frac{Y_{0}^{-n}}{\left(\frac{1}{R_{s}}+\frac{1}{R_{c}}\right)^{\frac{(n-1)}{n}}} \\
C_{d l} & =\frac{Y_{0}^{-n}}{\left(\frac{1}{R_{s}}+\frac{1}{R_{d l}}\right)^{\frac{(n-1)}{n}}}
\end{aligned}
$$




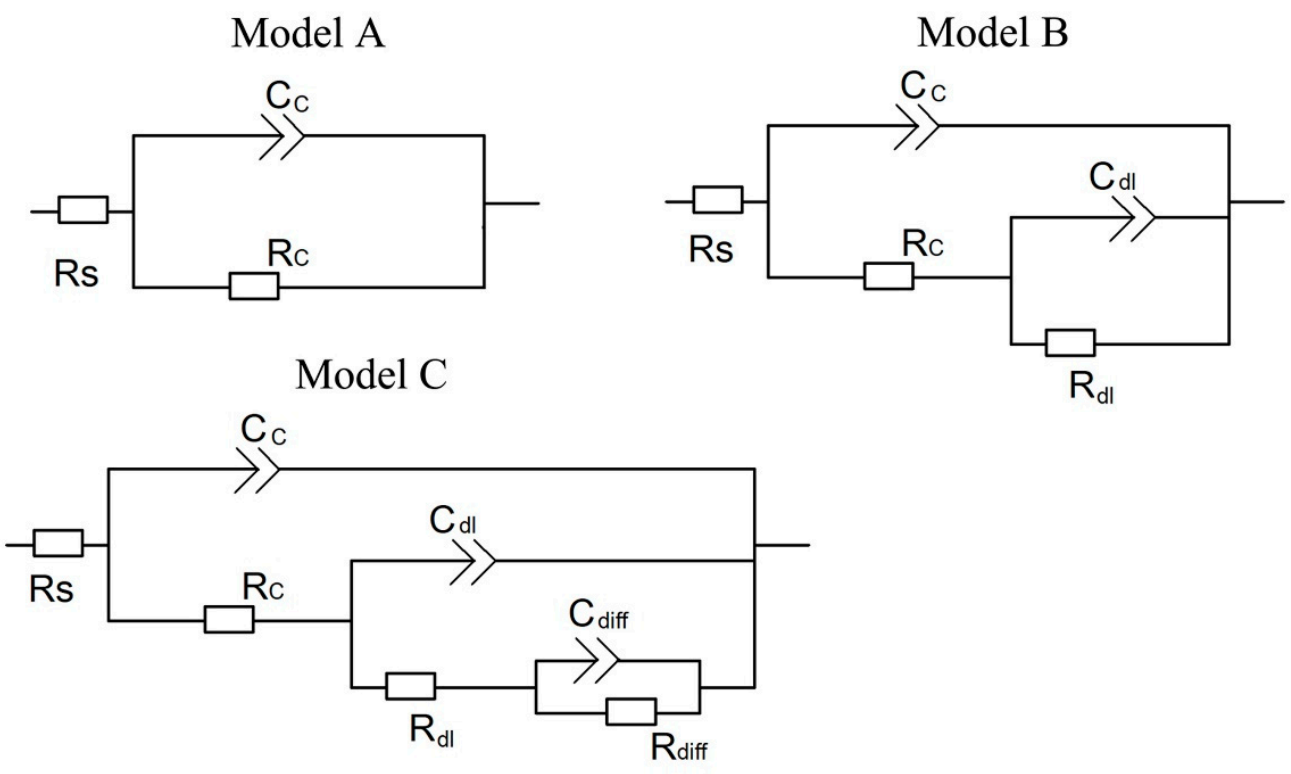

Figure 4. Equivalent electrical circuits used for numeric fitting of EIS data.

The fitted curves are illustrated in Figure 3. At the initial immersion time (30 min), using Model A could well fit the EIS data. Here, $R_{s}$ is the solution resistance, $C_{c}$ is the $P E$ coating capacitance, and $R_{c}$ is the PE coating resistance. After one day immersion, the EIS of coatings changed. Model B included the charge-transfer resistance $\left(R_{\mathrm{dl}}\right)$ and the double-layer capacitance $\left(C_{\mathrm{dl}}\right)$ was introduced to fit the intermediate frequencies spectrum. At this time, active corrosive ions had reached the coating/substrate interface through the top-coated PE coating, and the oxidation reduction reaction occurs at the $\mathrm{Al}$-alloy substrate. With the extension of immersion time, corrosive products begin to appear on the metal matrix for the coatings that had a barrier performance against the diffusion of corrosion products. Model $\mathrm{C}$ with the diffusion capacitance $\left(\mathrm{C}_{\mathrm{diff}}\right)$ and diffusion resistance $\left(\mathrm{R}_{\text {diff }}\right)$ was introduced to fit the spectroscopy.

The four electrochemical parameters of $C_{c}, R_{c}, C_{d l}$, and $R_{d l}$ are closely related to the electrochemical corrosion behavior of the coating $[7,11,12]$. $C_{c}$ is directly proportional to the barrier effect of coating on water. $R_{c}$ characterizes the total resistance of the electrolyte in the coated micropores or capillary channels [12]. With the penetration of electrolyte, $C_{c}$ increases and $R_{c}$ decreases. $R_{d l}$ and $C_{d l}$ are two important parameters that reflected the progress of corrosion reaction at the metal/electrolyte interface [27]. The smaller the $\mathrm{C}_{\mathrm{dl}}$ and the larger $\mathrm{R}_{\mathrm{dl}}$ values, the more effective the coating is in preventing the corrosion reactions of the metal surface. According to the fitting results, the changes of $C_{c}, R_{c}, C_{d l}$, and $R_{\mathrm{dl}}$ with immersion time are shown in Figure 5.

During the whole immersion test period, the $C_{C}$ values of silane prepolymer-modified coatings are much lower than that of PE coating, indicating that the silane prepolymermodified coatings can improve the barrier effect of coating on water. The BISE-PE coating had the lowest $C_{c}$ value (Figure $5 a$ ), and highest $R_{c}$ value (Figure $5 b$ ), indicating that the BISE-PE coating has the strongest penetration barrier ability [29]. The order of the stable $C_{\mathrm{dl}}$ values of the four coatings was: PE $>$ TEOS-PE $>$ GPTMS-PE $>$ BISE-PE, and the order of $R_{d l}$ from small to large is: $\mathrm{PE}<\mathrm{GPTMS}-\mathrm{PE}<\mathrm{TEOS}-\mathrm{PE}<\mathrm{BISE}-\mathrm{PE}$, indicating that the BISE-PE coating could effectively inhibit the corrosion reaction at the coating/metal interface. 


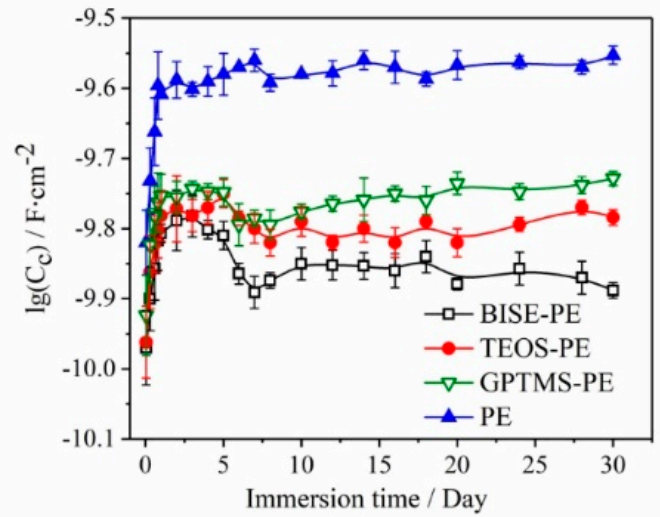

(a)

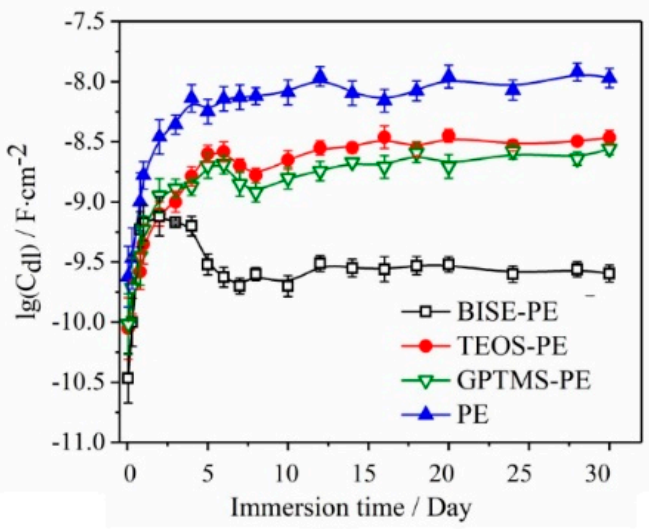

(c)

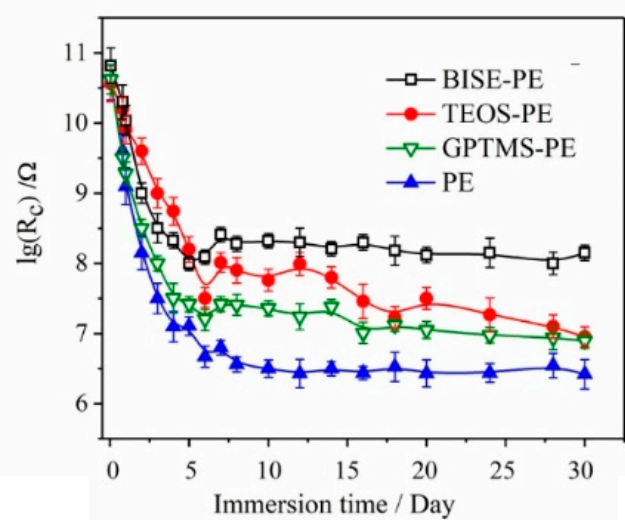

(b)

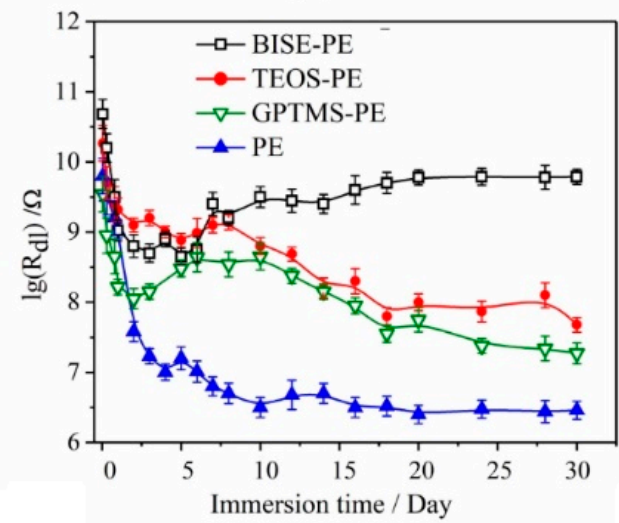

(d)

Figure 5. Evolution of the electrical parameters: (a) $C_{c},(b) R_{c},(c) C_{d l}$, and $(d) R_{d l}$, derived from EIS data.

\subsection{The Water Uptake in Silane-Epoxy Coatings}

Continuous migration of aggressive ions results in coating delamination and underfilm corrosion, and ultimately loss of corrosion protection of the organic coatings [30,31]. Water is a medium for diffusion of oxygen and corrosive ions. Therefore, the protective effect of the coating on the substrate can be characterized by the barrier of water transmission by the coating. Assuming that the water transport in the coating follows Fick's law, the water absorption in the coating can be calculated according to the equation of Brasher-Kingsbury [32]:

$$
\varnothing \omega=\frac{\log \left(\frac{C_{t}}{C_{0}}\right)}{\log \left(\varepsilon_{\omega}\right)}
$$

where $\varnothing \omega$ is the water volume fraction in the coating, $\varepsilon_{\omega}$ is the dielectric constant of water $\left(\varepsilon_{\omega}=80\right.$ at $\left.\mathrm{T}=20^{\circ} \mathrm{C}\right), \mathrm{C}_{\mathrm{t}}$ and $\mathrm{C}_{0}$ are the coating capacitance at time $t$ and zero, respectively.

Figure 6 shows the evolution of water sorption of four coatings during the immersion test time. It can be seen that compared with PE coating, the water absorption of silanemodified coatings had been greatly reduced, especially the BISE-PE coating decreased by ca. $50 \%$. The sharp decrease in water absorption of BISE-PE coating may be due to the polymer leaching and/or crosslinking reaction between silanol and epoxy groups [12-14]. 


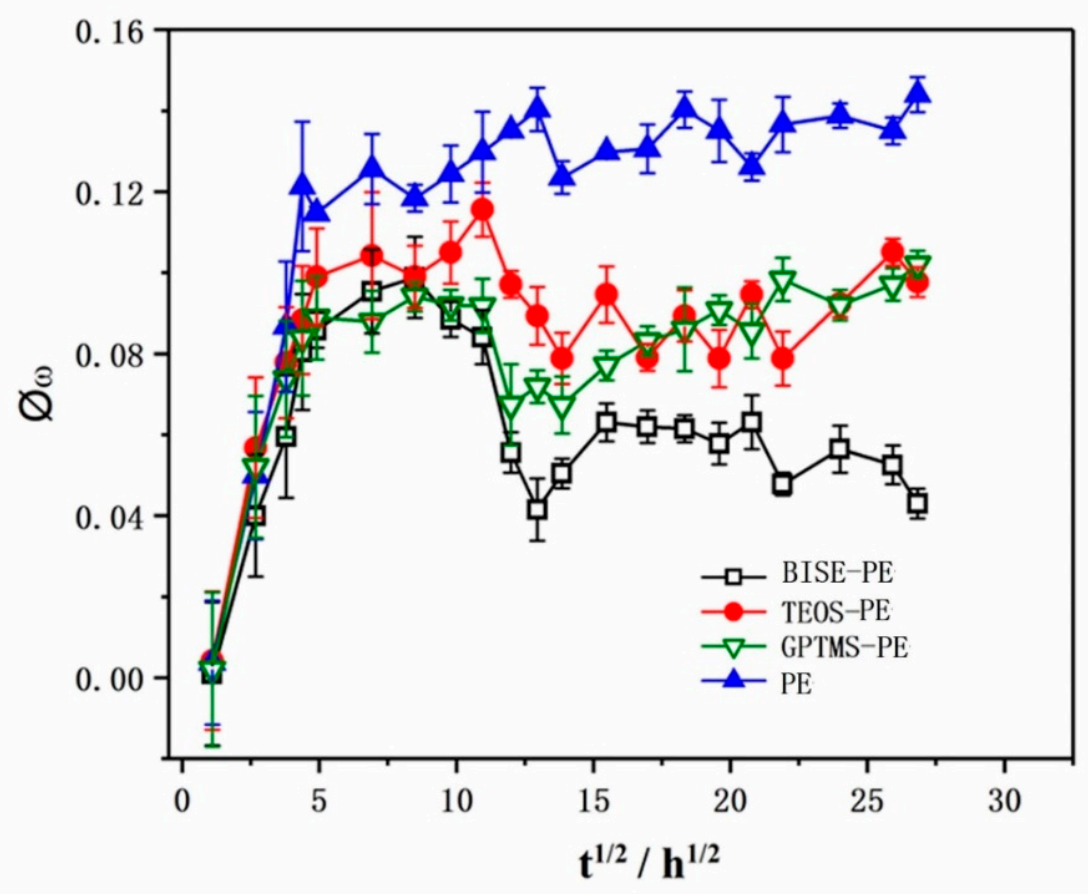

Figure 6. Evolution of water uptake of coatings.

\section{Conclusions}

Bis-silane-modified epoxy coatings were prepared on $\mathrm{Al}-\mathrm{Zn}-\mathrm{Mg}-\mathrm{Cu}$ alloy in the present work. Following points were observed:

(1) Due to the leaching of the incompletely hydrolyzed siloxane in the coating, the phenomenon of "self-healing" occurs in the silane-modified coating system, especially the BISE-PE coating had better "self-healing" ability. The improvement of the "self-healing" ability of the BISE-PE coating was not only due to the network formed by the hydrolytic polycondensation of the hydrolyzable alkoxy groups, but also due to the cross-linking reaction between different silanes in the long-term immersion process.

(2) The BISE-PE coating shows the lowest coating capacitance $\left(\mathrm{C}_{c}\right)$ and double-layer capacitance $\left(C_{\mathrm{dl}}\right)$, and the highest charge transfer resistance $\left(\mathrm{R}_{\mathrm{dl}}\right)$ after long-time immersion, indicating that the BISE-PE coating has the strongest waterproof permeability and corrosion resistance.

Author Contributions: Data curation, D.Z.; formal analysis, D.Z.; investigation, H.W.; project administration, Z.L. and L.Z.; software, D.Z. and L.Z.; writing-review and editing, D.Z. All authors have read and agreed to the published version of the manuscript.

Funding: This research was funded by the Scientific Research Fund of Hunan Provincial Education Department(20K112); Research Fund Education Department of Hunan Province, China (18B421); National Key Research and Development Program of China (2016YFB0300900); The Opening Foundation Key Laboratory of Hunan Province for Efficient Power System and Intelligent Manufacturing (No.19KF01).

Institutional Review Board Statement: Not applicable.

Informed Consent Statement: Not applicable.

Data Availability Statement: Data sharing not applicable.

Conflicts of Interest: There are no conflicts of interest to declare. 


\section{References}

1. Bierwagen, G.P.; Twite, R.; Chen, G.; Tallmanb, D.E. Atomic force microscopy, scan-ning electron microscopy and electrochemical characterization of $\mathrm{Al}$ alloys, conversion coatings, and primers used for aircraft. Prog. Org. Coat. 1997, 32, 25-30. [CrossRef]

2. Yerokhin, A.L.; Nie, X.; Leyland, A.; Matthews, A.; Dowey, S.J. Plasma electrolysis for surface engineering. Surf. Coat. Technol. 1999, 122, 73-93. [CrossRef]

3. Dehnavi, V.; Shoesmith, D.W.; Luan, B.L.; Yari, M.; Liu, X.Y.; Rohani, S. Corrosion properties of plasma electrolytic oxidation coatings on an aluminium alloy-The effect of the PEO process stage. Mater. Chem. Phys. 2015, 161, 49-58. [CrossRef]

4. Chen, M.A.; Ou, Y.C.; Fu, Y.H.; Li, Z.H.; Li, J.M.; Liu, S.D. Effect of friction stirred Al-Fe-Si particles in 6061 aluminum alloy on structure and corrosion performance of MAO coating. Surf. Coat. Technol. 2016, 304, 85-97. [CrossRef]

5. Miszczyk, A.; Schauer, T. Electrochemical approach to evaluate the interlalyer adhesion of organic coatings. Prog. Org. Coat. 2005, 52, 298-305. [CrossRef]

6. Zhang, J.T.; Hu, J.M.; Zhang, J.Q.; Cao, C.N. Studies of impedance models and water transport behaviors of polypropylene coated metals in $\mathrm{NaCl}$ solution. Prog. Org. Coat. 2004, 49, 293-301. [CrossRef]

7. Yuan, X.; Yue, Z.F.; Chen, X.; Wen, S.F.; Li, L. Effect of mixture ratio on water uptake and corrosion performance of silicone-epoxy hybrid coatings coated 2024 Al-alloy. Prog. Org. Coat. 2015, 78, 168-175. [CrossRef]

8. Ma, Y.; Di, H.; Yu, Z.; Liang, L.; Lv, L.; Pan, Y.; Yin, D. Fabrication of silica decorated graphene oxide nanohybrids and the properties of composite epoxy coatings research. Appl. Surf. Sci. 2016, 360, 936-945. [CrossRef]

9. Yu, Z.; Di, H.; Ma, Y.; Lv, L.; Pan, Y.; Zhang, C.; He, Y. Fabrication of graphene oxide-alumina hybrids to reinforce the anti-corrosion performance of composite epoxy coatings. Appl. Surf. Sci. 2015, 351, 986-996. [CrossRef]

10. Zhang, J.T.; Hu, J.M.; Zhang, J.Q.; Cao, C.N. Studies of water transport behavior and impedance models of epoxy-coated metals in NaCI solution by E1S. Prog. Org. Coat. 2004, 51, 145-151. [CrossRef]

11. Hu, J.M.; Zhang, J.Q.; Cao, C.N. Reducing the water absorption in epoxy coatings by silane monomer incorporation. Corros. Sci. 2006, 48,3731 .

12. Jiang, M.Y.; Wu, L.K.; Hu, J.M.; Zhang, J.Q. Silane-incorporated epoxy coatings on aluminum alloy (AA2024). Part 1: Improved corrosion performance. Corros. Sci. 2015, 92, 118-126. [CrossRef]

13. Wu, L.K.; Zhang, J.T.; Hu, J.M.; Zhang, J.Q. Improved corrosion performance of electrophoretic coatings by silane addition. Corros. Sci. 2012, 56, 58-66. [CrossRef]

14. Ji, W.G.; Hu, J.M.; Liu, L.; Zhang, J.Q.; Cao, C.N. Enhancement of corrosion performance of epoxy coatings by chemical modification with GPTMS silane monomer. J. Adhes. Sci. Technol. 2008, 22, 77-92. [CrossRef]

15. Wang, P.; Schaefer, D.W. Why does silane enhance the protective properties of epoxy films? Langmuir 2008, $24,13496-13501$. [CrossRef]

16. Jang, J.; Kim, E.K. Corrosion protection of epoxy-coated steel using different silane coupling agents. J. Appl. Polym. Sci. 1999, 71, 585-593. [CrossRef]

17. Ochi, M.; Takahashi, R.; Terauchi, A. Phase structure and mechanical and adhesion properties of epoxy/silica hybrids. Polymer 2001, 42, 5151-5158. [CrossRef]

18. Bakhshandeh, E.; Jannesari, A.; Ranjbar, Z.; Sobhani, S.; Saeb, M.R. Anti-corrosion hybrid coatings based on epoxy-silicananocomposites: Toward relationship between the morphologyand EIS data. Prog. Org. Coat. 2014, 77, 1169-1183. [CrossRef]

19. Tan, A.L.K.; Soutar, A.M.; Annergren, I.F.; Liu, Y.N. Multilayer sol-gel coatings for corrosion protection of magnesium. Surf. Coat. Technol. 2005, 198, 478-482. [CrossRef]

20. Yuan, X.; Yue, Z.F.; Liu, Z.Q.; Wen, S.F.; Li, L.; Feng, T. Effect of siloxane-modified polyacrylate on water uptake and anticorrosion mechanism of silicone-epoxy coatings. J. Coat. Techol. Res. 2016, 13, 123-132. [CrossRef]

21. Whelan, M.; Cassidy, J.; Duffy, B. Sol-gel sealing characteristics for corrosion resistance of anodised aluminium. Surf. Coat. Technol. 2013, 235, 86-96. [CrossRef]

22. Guo, X.; Du, K.; Guo, Q.; Wang, Y.; Wang, R.; Wang, F. Study of barrier property of composite film coated on Mg-Gd-Y alloy by water diffusion. ECS Electrochem. Lett. 2013, 2, C27-C30. [CrossRef]

23. Bajat, J.B.; Milošev, I.; Jovanović, Ž.; Jančić-Heinemann, R.M.; Dimitrijević, M.; Mišković-Stanković, V.B. Corrosion protection of aluminium pretreated by vinyltriethoxysilane in sodium chloride solution. Corros. Sci. 2010, 52, 1060-1069. [CrossRef]

24. Frignani, A.; Zucchi, F.; Trabanelli, G.; Grassi, V. Protective action towards aluminium corrosion by silanes with a long aliphatic chain. Corros. Sci. 2006, 48, 2258-2273. [CrossRef]

25. Zheludkevich, M.L.; Tedim, J.; Freire, C.S.R.; Fernandes, S.C.; Kallip, S.; Lisenkov, A.; Ferreira, M.G.S. Self-healing protective coatings with "green" chitosan based pre-layer reservoir of corrosion inhibitor. J. Mater. Chem. 2011, 21, 4805-4812. [CrossRef]

26. Zheludkevich, M.; Yasakau, K.A.; Bastos, A.C.; Karavai, O.V.; Ferreira, M.G.S. On the application of electrochemical impedance spectroscopy to study the selfhealing properties of protective coatings. Electrochem. Commun. 2007, 9, 2622-2628. [CrossRef]

27. Yuan, X.; Yue, Z.F.; Chen, X.; Wen, S.F.; Li, L.; Feng, T. The protective and adhesion properties of silicone-epoxy hybrid coatings on 2024 AL-alloy with a silane film as pretreatment. Corros. Sci. 2016, 104, 84-97. [CrossRef]

28. Jiang, M.Y.; Wu, L.K.; Hu, J.M.; Zhang, J.Q. Silane-incorporated epoxy coatings on aluminum alloy (AA2024). Part 2: Mechanistic investigations. Corros. Sci. 2015, 92, 127-135. [CrossRef] 
29. Flis, J.; Kanoza, M. Electrochemical and surface analytical study of vinyltriethoxy silane films on iron after exposure to air. Electrochim. Acta 2006, 51, 2338-2345. [CrossRef]

30. Zhu, C.; Xie, R.; Xue, J.; Song, L. Studies of the impedance models and water transport behaviors of cathodically polarized coating. Electrochim. Acta 2011, 56, 5828-5835. [CrossRef]

31. Amand, S.; Musiani, M.; Orazem, M.E.; Pébère, N.; Tribollet, B.; Vivier, V. Constant-phase-element behavior caused by inhomogeneous water uptake in anti-corrosion coatings. Electrochim. Acta 2013, 87, 693-700. [CrossRef]

32. Brasher, D.M.; Kingsbury, A.H. Electrical measurements in the study of immersed paint coatings on metal. I. Comparison between capacitance and gravimetric methods of estimating water uptake. J. Appl. Chem. 1954, 4, 62-72. [CrossRef] 